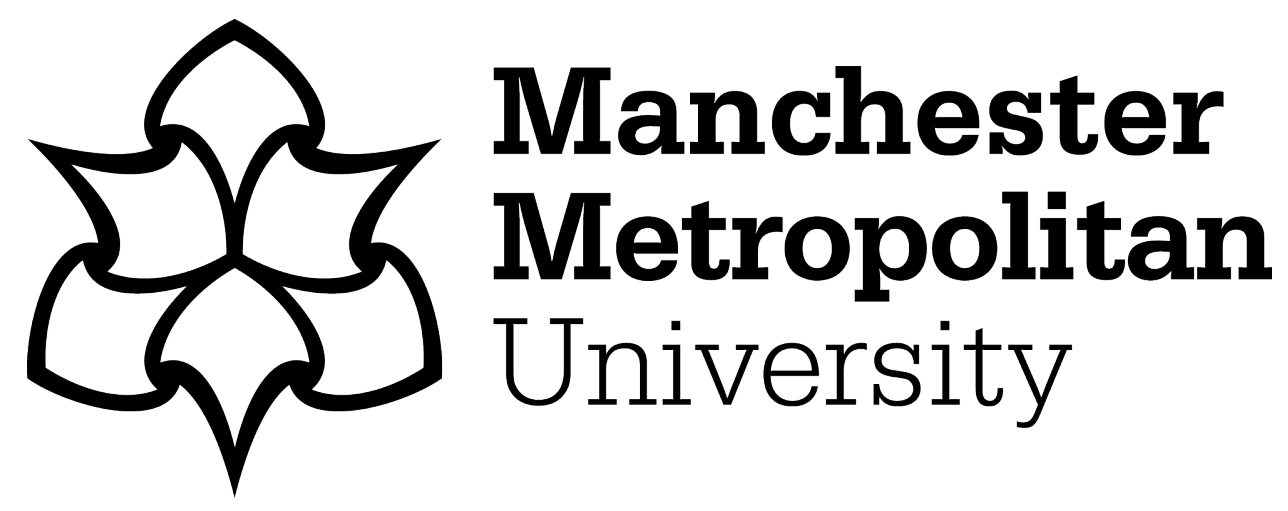

Cooke, Mandy, Wong, Sandie and Press, Frances ORCID logoORCID: https://orcid.org/0000-0002-8980-5096 (2020) High quality educators' conceptualisation of children's risk-taking in early childhood education: provoking educators to think more broadly. European Early Childhood Education Research Journal, 28 (3). pp. 424-438. ISSN 1350-293X

Downloaded from: https://e-space.mmu.ac.uk/626186/

Version: Accepted Version

Publisher: Informa UK Limited

DOI: https://doi.org/10.1080/1350293x.2020.1755499

Please cite the published version 


\title{
High quality educators' conceptualisation of children's risk-taking in early childhood education: Provoking educators to think more broadly
}

\author{
Mandy Cooke $e^{\mathrm{a}}$ and Sandie Wong ${ }^{\mathrm{b}}$ and Frances Press ${ }^{\mathrm{c}}$
}

${ }^{a}$ School of Education, Charles Sturt University, Wagga Wagga, Australia; ${ }^{b}$ Department of Educational Studies, Macquarie University, Sydney, Australia; ' School of Childhood, Youth and Education Studies, Manchester Metropolitan University, England Mandy Cooke, Charles Sturt University, Boorooma St, North Wagga Wagga NSW 2650, Australia. Email: acooke@csu.edu.au

\begin{abstract}
Children's risk-taking is increasingly acknowledged as an important part of early childhood education. Previous research has predominantly focussed on children's engagement with, and educators' perspectives on, children's risk-taking in outdoor physical play. However, little attention has been paid to how educators conceptualise children's risk-taking more broadly. Our study addresses this research gap. A three-site case study, the research gathered data from educators in high quality early childhood services through observations and interviews. Findings show that educators predominantly framed children's risk-taking as taking place in physical and outdoor play. However, with minimal provocation, educators extended their conceptualisations of risk to encompass a broader range of children's experiences. Data suggests that participation in the research provoked many participants to think more broadly about children's risk-taking.
\end{abstract}

Keywords: children's risk-taking; risky play; early childhood education and care; educators' conceptualisations; professional development

\section{Introduction}

The value of children's healthy risk-taking in early childhood education (ECE) has been acknowledged in research and early childhood literature (Ball, Gill, and Spiegal 2012, Gleeve 2008, Little, Sandseter, and Wyver 2012). Children's risk-taking is now included in many early childhood curriculum documents around the world (See Australian Government Department of Education Employment and Workplace 
Relations [DEEWR] 2009, Department for Education and Skills 2015, Makovichuk et al. 2014). Hence there is an increased expectation upon early childhood educators to understand, provide for and support children's risk-taking. Previous research on children's risk-taking in ECE has focused on risk-taking in outdoor physical play, commonly known as risky play (Sandseter 2009b, Little 2010b, McFarland and Laird 2017). Within risky play research, researchers have explored children's experiences with risky play and educators' perspectives and attitudes toward children's risky play (McFarland and Laird 2017, Little, Sandseter, and Wyver 2012, Sandseter 2014). To the best of our knowledge, no research has investigated educators' universal conceptualisations of children's risk-taking. We propose that educators' conceptualisation of where, how and in what kinds of experiences children engage with risk-taking may influence their practices. As proposed elsewhere, we are concerned that the predominant focus on children's risk-taking in outdoor physical play may have caused educators to have a narrow conceptualisation of children's risk-taking and this may have led to limitations in educators' practices (Cooke, Wong, and Press 2019).

In this article, we share findings of a qualitative multi-site case study that explored educators' conceptualisations of children's risk-taking in ECE. The study focused on educators in high quality early childhood services that expressly value children's healthy risk-taking. Given the narrow focus of previous studies, the findings reported here focus on whether educators in these high quality services viewed children's risk-taking as an outdoor physical play activity, in line with the extant literature, or did they identify children's risk-taking as broader than this?

\section{Background}

The disposition to take healthy risks is increasingly being regarded as a positive character trait (Dweck 2012, Brown 2015). Healthy risk-taking can be defined as voluntarily engaging in experiences that take a person outside of their comfort zone and have potential benefits to learning, development and life satisfaction (Cooke, Wong, and Press 2019). Healthy risk-taking can take place in innumerable domains of life (Adams 1995). Risk-taking can be physical, emotional, social, intellectual or financial (Lupton 2013, Smith 1998). Risk-taking can take place indoors as well as outdoors (Saunders 2016, New, Mardell, and Robinson 2005, Kleppe 2018). Common characteristics of risk-taking include uncertainty (Trimpop 1994, Adams 1995); the 
possibility of either positive or negative consequences (Doron 2016, Madge and Barker 2007); the possibility of failure (Little and Eager 2015, Stephenson 2003); and a balance of fear and excitement (Sandseter 2009b). Whether an act is considered risky is also based on individual risk perception. Risk perception is the subjective assessment of the likelihood of negative consequences and how concerned we are with those consequences (Sjöberg, Moen, and Rundmo 2004, Ostrom and Wilhelmsen 2012). Risk perception deems that what one person perceives as risky another may not. Risk perception is based on a range of factors including culture, gender, age and past experience (Burgess, Alemanno, and Zinn 2016, Adams 1995, Sjöberg, Moen, and Rundmo 2004, Trimpop 1994). Risk perception varies across domains (Zuckerman 2000, Schoemaker 1990, Blais and Weber 2006) and researchers advocate investigation of risk-taking across multiple domains (Tyagi et al. 2017).

ECE risk research has predominantly focused on risk-taking in the physical domain, in the form of risky play. Risky play, defined as a 'thrilling and exciting form of play that involves a risk of physical injury' (Sandseter 2009a, 439), has principally been explored in outdoor environments. Leading risky play researcher, Sandseter (2007) focused on the way children interacted with features of outdoor environments that might invite physical risk-taking to identify common examples of children's physical risky play. Sandseter identified six categories of risky play: 1. Play with great height; 2. Play with high speed; 3 . Play with dangerous tools; 4 . Play with dangerous elements; 5. Rough and tumble play; and 6. Play where one might disappear or get lost. The term risky play, Sandseter's definition of risky play and the six categories have been used by researchers to explore educators' perspectives on children's risky play (Sandseter 2014, McFarland and Laird 2017, Little 2010a). Studies show that educators recognise that children regularly engage in risky play (Sandseter 2014) and that many educators feel they provide for and support children's engagement with risky play (McFarland and Laird 2017). Although there is a growing body of research telling us about educators' perspectives and attitudes toward children's risky play, we could only locate one empirical study involving children's risk-taking beyond physical risk. In an article proposing the notion of a risk-rich curriculum, New, Mardell, and Robinson (2005) reveal educators in their study recognised children may take risks when entering, forming and negotiating relationships. Although this study involved children's risktaking beyond outdoor physical risk, it does not give us a broad understanding of 
educators' conceptualisations of children's risk-taking or their views on specific types of risk-taking, such as risk-taking indoors or social and emotional risk-taking. As we have argued elsewhere, a comprehensive conceptualisation of children's risk-taking may aid educators in providing for and supporting a broad range of healthy risk-taking experiences for children (Cooke, Wong, and Press 2019).

To support our analysis, we have drawn on definitions of risk-taking in the physical, social, emotional and cognitive domains. Physical risk-taking has been defined as engaging in 'a behaviour that could result in physical injury when there are alternative behaviours that do not do so' (Morrongiello, Walpole, and Lasenby 2007). Examples include walking at height or moving at speed. Emotional risk-taking has been defined 'as placing oneself in an emotionally vulnerable position... when the anticipated outcome is unpredictable or undesirable' (Carter and Carter 2010). Emotional risktaking might involve expressing ones' feelings or entering a relationship. Social risktaking has been described as taking risks within a social context, or through the influence of a social context (Bougheas, Nieboer, and Sefton 2013). Social risk-taking might include making a decision consistent with or in opposition to a peer group. And finally, cognitive risk-taking has been described as 'working on the edge of one's competence', such as one might do in the process of creating something new (Bereiter 1993, 33). These definitions, along with the common characteristics of risk-taking described above, have been used to analyse educators' conceptualisations of children's risk-taking.

\section{Current Study}

\section{Case and Participants}

The research under discussion was a qualitative multi-site case study of three high quality Australian ECE services that expressly value children's healthy risk-taking. The rationale for selecting high quality services was to ensure that data identified insights associated with high quality ECE. The rationale for selecting services that expressly value children's healthy risk-taking was that this placed participant educators in the best position to offer insight on children's risk-taking. Selection of high quality services was based on the Australian Children's Education and Care Authority assessment and rating process (Australian Children's Education and Care Quality Authority [ACECQA] 
2017). A list of services that had achieved an exceeding rating in every quality area and available standard from the assessment and rating process was obtained from ACECQA. From this list, two states were selected (the state of the location of the researcher and a second state for a wider perspective) to review services' views on children's healthy risk-taking. The review involved assessing publicly available information such as philosophy, curriculum information, newsletters and photos against a 'risk indicator checklist' compiled from the literature. 304 services were reviewed against the checklist and 40 were selected for a short list. From the short list, the two highest scored services in the researcher's state and the highest scored service in the additional state were invited to participate. All three services agree to participate, and so no further services were contacted.

The three participating services consisted of 1) a community run long day care ${ }^{1}$ centre located in a major city suburb, with 140 children's places and 40 educators; 2) a community run sessional kindergarten ${ }^{2}$ located in a regional town, with 54 children's places and nine educators; and 3) a privately owned not-for-profit long day care centre located in a regional town, with 100 children's places and 33 educators. A total of 55 educators participated. Educators were between 18 and 61 years of age; 15 held Certificate III $^{3}, 30$ held Diplomas ${ }^{4}, 7$ held Bachelors' Degrees ${ }^{5}$ and 3 held Masters' Degrees. Participating educators' experience in ECE ranged from 6 months to 38 years.

${ }^{1}$ Long Day Care services in Australia are centre-based services offering all day ECE for children from birth to five years of age.

${ }^{2}$ Sessional kindergartens in Australia are centre-based services primarily offering funded kindergarten programs aimed at children in the year before school.

${ }^{3}$ Certificate III is a six month qualification and is the minimum requirement in Australia to work in long day care or as an assistant in a kindergarten program.

${ }^{4}$ Diploma is a 12-18 month course and is an advanced qualification that enables an educator in Australia to work as a room leader or centre manager in long day care or as an assistant in a kindergarten program.

${ }^{5}$ Bachelor's Degree is a four year academic undergraduate degree and is required to work as a teacher in an Australian kindergarten program. 


\section{Ethics}

Following approval from Charles Sturt University's research ethics committee, issues of confidentiality and consent were addressed. All educators working in the selected services were invited to participate via both verbal and written information. Educators gave consent to participate via a consent form. All families were given written information and invited to give consent for their child to be observed and photographed. Families and educators were asked to communicate information about the study with children, including their right to assent and dissent. In educator and family written information it was made clear that neither educators or children would be encouraged to engage in any risk-taking activities or experiences other than those normally part of their daily practices. The lead author, who carried out data collection, was aware that during observations she may be faced with the decision whether to intervene in children's activities to maintain children's safety and wellbeing. There were no times during data collection when she felt this decision was necessary and no child was injured during observations.

\section{Prior to data collection}

Prior to data collection in each of the services, the lead author shared information about the purpose of the study with participants. This information included a brief summary of the reviewed literature, the aims and scope of the study and a short narrative that provided an example of non-physical risk-taking. The information provided appeared influential in the results, as will be evident in the findings and discussion section of this paper.

\section{Data collection}

Data were collected through observations, in-situ interviews and formal interviews.

Data were collected over a period of eight months, with between six and 19 days spent in each service, with more time spent in larger services. Observations were conducted in both the indoor and outdoor spaces of all services. Observations were guided by a specially designed list of observable risk indicators. The list was made up of common characteristics of risk-taking as identified in the literature (Trimpop 1994, Adams 1995, Doron 2016, Madge and Barker 2007, Little and Eager 2015, Stephenson 2003, Sandseter 2009b). Children's activities that the researcher perceived to include risk- 
taking characteristics were described in field notes and photographed. In-situ and formal interviews were then used to gather educators' insights. In-situ interviews took place alongside observations in which the researcher pointed out examples of possible risktaking and asked educators to comment and provide examples of their own.

In-situ interview questions included:

- Can you tell me about this experience?

- What do you think might be the risk in this experience?

Formal interviews were conducted toward the end of the data collection period in each service. There were 25 one-to-one formal interviews and 10 group interviews, with groups consisting of between two and six educators. Formal interviews were approximately one hour in length and took place in a room or space away from other educators and children. Educators were selected for interviews with the aim of achieving a balance across class groups (babies, 1-3 years, 4-5 years) and qualifications (Cert III, Diploma, Bachelor/Masters). Formal interviews were semi-structured using open-ended questions. Formal interview questions included:

- How would you describe or define risk-taking?

- Can you tell me about children's risk-taking?

- Can you give me examples of children's risk-taking?

During formal interviews, participants were also shown the photos taken during observations as a way of stimulating further discussion. Interviews were recorded, transcribed and returned to participants for member checking prior to data analysis.

\section{Data Analysis}

Data were analysed using thematic analysis. Thematic analysis provides a flexible method for identifying themes within data (Braun and Clarke 2006). Data analysis proceeded in three phases. The first phase involved a read through of field notes and transcribed interviews. During this read through, notes were taken regarding possible themes. In the second phase, field notes and interviews were coded using NVIVO. Coding focused on educators' examples of experiences that might involve risk-taking. Themes identified during the initial read through were combined with themes identified in the literature. Additional themes were added throughout the coding process. Themes included social and emotional risk-taking and risk-taking indoors. Phase three involved a combination of inductive and deductive thematic analysis to identify key themes and patterns and draw final conclusions. Some counting of educators' examples of 
children's risk-taking was done to identify prevalence of types of risk-taking and to validate researcher deductions.

\section{Findings and Discussion}

Analysis of the data revealed two key findings. First, most educators' initial conceptualisation of children's risk-taking was as outdoor and physical risky play. Second, with minimal provocation most educators articulated a broader conceptualisation of children's risk-taking. Before addressing these findings, we summarise educators' description of risk-taking as a way of framing the discussion. In the findings and discussion below, pseudonyms have been used for all educators and children.

\section{Educators' description of risk-taking}

When educators were asked how they would describe or define risk-taking, the word most commonly used was challenge. Educators' saw risk-taking as the challenge to do something new, something uncertain or something out of ones' comfort zone. Another commonly used description was pushing boundaries. Educators described risk-taking as experimenting and doing something uncomfortable or fearful, something that required bravery and the ability to push through fear and discomfort. The possibility of danger or harm was also a common theme, as was the idea that risk-taking presents opportunities and possibilities such as exploration and adventure.

'I think it's anything that scares you a bit. Whether it's risk of failure, risk of hurting yourself, risk of hurting someone else. It's fear of....any of those fears that are on that long list of fears that you can find' Polly

'You put yourself in spaces that you feel uncomfortable...you just have that little bit of churning in the tummy...that's what risk-taking is' Jane

Most educators said that risk-taking is an inherent and unavoidable part of life and all educators expressed a positive attitude toward children's risk-taking. Most educators said that risk is something that is perceived by the individual and that all individuals are different. Many educators said they could only guess at whether an experience was risky for a child as they were 'not in the child's head'. They said that the way an 
individual perceives risk is based on a range of factors such as experience, competence and confidence. Although educators described risk-taking as a challenge, they did not see all challenges as taking a risk. There were often times when educators said they couldn't identify any child engaged in an activity that might be considered risk-taking. We now turn to the two key findings, based on examples educators gave of children's possible engagement in risk-taking.

\section{Risk-taking as risky play}

The first key finding was that most educators' first and most common examples of children's risk-taking were related to physical and outdoor play. During observations, the researcher routinely asked educators Have you seen any children engage in risktaking today? Regardless of whether this question was asked outdoors or indoors, educators most commonly mentioned children's physical and outdoor activities. The most common outdoor example was climbing. The most common indoor example was using scissors. When in-situ interviews were conducted indoors, some educators still gave examples of outdoor risk-taking or said that they had not seen any risk-taking. One educator explicitly stated that she had not seen any risk-taking because she had 'been inside all day'. During formal interviews away from children, educators also mostly spoke about children's risk-taking in physical and outdoor play. Comments included ' $I$ think [about] risk-taking [as] physical [and] outside' and 'I gravitate towards physical things that could injure'. One educator expressed that she did not see indoor experiences as something that might involve risk-taking 'I think risk-taking is more outdoors...I don't really see those things as risks inside'. This finding suggests that most educators initially conceptualised children's risk-taking as a physical and outdoor activity, in line with the notion of risky play (Sandseter 2009a). This may be explained in several ways. First, because the dominant discourse on children's risk-taking is in outdoor physical risky play (Little 2010a, Sandseter 2009a, Stephenson 2003). Second, because physical risk-taking is tangible and therefore easy to recognise. Third, because the professional development that has introduced educators to children's risk-taking focuses on outdoor physical risky play. Educators' experiences with professional development were explored as part of the research.

Most educators reported having participated in professional development that included information about risky play, although no educator reported participating in 
professional development with a principal focus on children's risk-taking. The professional development sessions reported as influential were those focussed on outdoor nature pedagogy. In service one, all staff had participated in at least two whole staff professional development sessions that included some information about risky play. In service two, the two lead educators had participated in several outdoor nature pedagogy professional development sessions, leading to the development of an outdoor pedagogy program in the service. In service three, many educators had attended a professional development session with a leading nature pedagogy consultant who is known for including information on risky play (Lapkin 2015). Those who had not attended professional development themselves had been introduced to ideas about children's risk-taking by leaders or colleagues who had attended professional development. The combination of the dominant discourse on children's risk-taking as risky play, physical risk-taking being tangible and therefore easy to recognise, and the focus on risky play in outdoor nature pedagogy professional development is consistent with educators' conceptualisation of children's risk-taking as an outdoor physical play activity. By focusing on risky play, educators may have failed to recognise or spend time reflecting on other possible types of risk-taking. It is possible that this has led educators to overlook opportunities to provide, support and encourage a broad range of children's risk-taking.

Despite the dominance of outdoor physical play in ECE research and professional development, risk research outside of ECE tells us that risk-taking is more than an outdoor physical activity (Lupton 2013, Adams 1995) and some ECE authors have proposed children's risk-taking may take place indoors and in non-physical activities (Stephenson 2003, Tovey 2007, Rinaldi 2006). A small amount of research tells us that risky play can take place indoors (Kleppe 2018, Saunders 2016) and that risk-taking may not just be physical (New, Mardell, and Robinson 2005). The researcher herself has observed children engaged in a range of experiences she thought could be considered risky, including the example she gave to educators prior to data collection. In light of this, when investigating educators' conceptualisations of children's risk-taking, we were interested in examining whether educators' conceptualisations would encompass more than outdoor physical risky play. When educators' initial responses revealed a predominant focus on outdoor physical risky play, the researcher probed more deeply by asking questions such as Can you tell me 
about any risks the children could be taking indoors? Can you tell me about any risks the children could be taking that are not physical? Do you think the children do things during the day that you wouldn't consider play and if so, do you think the children take risks in these activities? These probing questions provoked the second key finding.

\section{A broad conceptualisation of children's risk-taking}

The second key finding is that with minimal provocation, participant educators conceptualised children's risk-taking as more than outdoor physical risky play. Educators recognised that in addition to outdoor and physical risky play, children may take risks indoors, in non-play activities and in non-physical domains.

\section{Risk-taking indoors}

Most educators identified indoor examples of children's risk-taking. Common examples included rough and tumble play, using tools such as knives and scissors, playing a new game, attempting a new puzzle, asking someone to play and contributing ideas. These examples all point to one or more of the common characteristics of risk-taking as described earlier. For example, using a knife has the possibility of negative consequences (Doron 2016, Madge and Barker 2007) through physical injury and attempting a puzzle has the possibility of failure (Little and Eager 2015, Stephenson 2003 ) as the child may not be able to complete the puzzle. One educator said that it is the activity that creates the possibility for risk-taking, rather than the location. By the completion of data collection, educators had provided close to equal number of examples of children's risk-taking indoors as outdoors. Participants recognition that children may take risks indoors is consistent with Kleppe (2018) and Saunders (2016) recent findings that risky play takes place indoors. Apart from New et al.'s (2005) study, research is yet to explore non-physical forms of children's risk-taking indoors. Our findings support Kleppe and Saunders' argument that it is important to consider indoor environments when researching children's risk-taking.

\section{Risk-taking in non-play activities}

To explore whether educators conceptualise risk-taking as a play activity, we asked educators whether they viewed any of the children's activities as something other than play. Most educators said that they view children's activities as play. Some educators, however, spoke about real work, skill acquisition and self-help tasks as having the 
possibility for risk-taking. The following example shows an educator's awareness that a child may be taking a risk when making sandwiches.

Example One: Making sandwiches

Polly- He wasn't too confident yet to cut with the big knife, so he asked me to help him...it was a big serrated one that they cut the bread with. But then after a while I said, 'Do you know what, how about I start with you and then as you start, I'm just going to take my hands away, but I'll tell you'. And then after that he was fine.

Researcher- So how would you describe that risk for the child?

Polly- That particular child...is very quiet and well-mannered and so [being] confident to be able to ask for help... Maybe he thought that [he needed to make] perfect triangles, because I do tell them that (laughs).

Polly described making sandwiches as an example of real work rather than play. Polly suggested the child in this example may be taking a risk by doing things he was not yet confident in, this being asking for help and cutting perfect triangle sandwiches. Cutting sandwiches may also be considered risk-taking due to the possibility of physical injury and, in this example, the possibility of failure (Little and Eager 2015, Stephenson 2003, Sandseter 2009a) in that the child might not succeed in cutting perfect sandwiches. This example could be viewed as cognitive risk-taking because the child, as articulated by Polly, was working on the edge of his ability when he asked for help (Bereiter 1993). Polly described gardening, helping to build a creek bed and refilling the sandpit as additional real work experiences that could involve risk-taking.

Some educators suggested children may take risks in skill acquisition or selfhelp tasks such as eating together, serving food, using real crockery and glassware, sewing and lighting a fire. Some educators were explicit in their description of these activities as non-play. Lighting a fire, for example, was described by one educator as 'not a play thing to do'. A child lighting a fire points to risk-taking because it has the possibility of failure (Little and Eager 2015, Stephenson 2003), this being the child may not succeed in lighting the fire. Fire lighting also points to physical risk-taking because it has the risk of physical injury (Morrongiello, Walpole, and Lasenby 2007) and cognitive risk-taking because the child is doing something they have not yet mastered and therefore working on the edge of their ability (Bereiter 1993). Some educators 
talked about skill acquisition and self-help tasks as containing emotional or social risktaking, such as taking the risk to try new foods or to socialise with new people during meal times. These findings demonstrate that children's risk-taking encompasses more than play, as inferred by the term risky play, and expose an unexplored area of children's risk-taking.

\section{Non-physical risk-taking}

When asked to think about whether children take risks that are not physical, many educators provided examples. One of the most common examples was in friendships. In the following example an educator identified that a child may take a risk when asking others to play.

Example Two: Can I be your best friend?

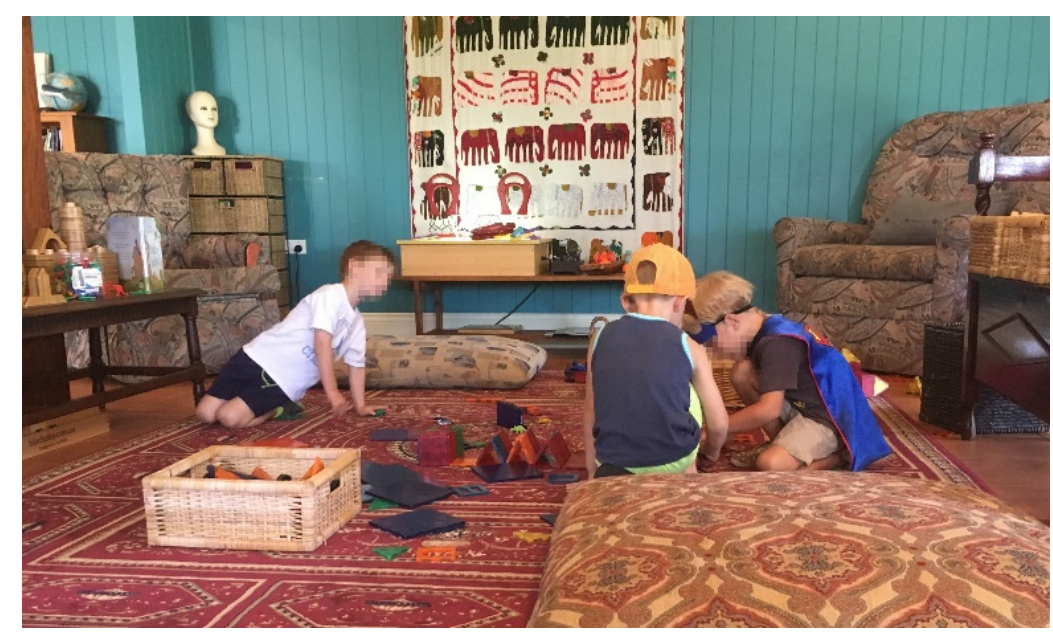

Observation:

Mark (white shirt)- Can I be your best friend?

Peter (hat)- No

In-situ interview with educator following this observation:

Valerie- I do think there's risk, particularly for the one that's left out. For their selfesteem.

In this example, Valerie indicates that she viewed Mark's action as risk-taking because it resulted in him being 'left out', this being a negative consequence. The question also had the possibility of positive consequences (Mark being included in the play), thus pointing to one of the common characteristics of risk-taking (Doron 2016, Madge and Barker 2007). Mark's question also contained uncertainty in that he didn't 
know how Peter was going to respond (Trimpop 1994, Adams 1995). Mark may have also experienced mixed feelings of fear and excitement (Sandseter 2009b) - excitement at the possibility of being able to join the play and fear at the possibility of being rejected. This example points to both social and emotional risk-taking. Mark put himself in an emotionally vulnerable position (Carter and Carter 2010) within a social context (Bougheas, Nieboer, and Sefton 2013) when he exposed himself to the possibility of rejection.

Additional examples of children's possible risk-taking in friendships included making suggestions in play, sharing ideas and doing things because that is what friends are doing. Educators saw these actions as risk-taking because they contained uncertainty (Trimpop 1994, Adams 1995) and the possibility of positive or negative consequences (Doron 2016, Madge and Barker 2007). Educators suggested negative consequences could include having an idea rejected, being laughed at or made to feel silly. One educator said that for children, 'learning to navigate their way socially and emotionally' was risky. Some educators suggested there are times when children need to be brave to stand up for what they want in play situations. The finding that educators believed children may take risks in friendships is in line with New et al.'s (2005) research showing that educators saw risk for children in entering, forming and negotiating relationships.

In addition to risk-taking in friendships, many educators gave examples of nonphysical risk-taking when a child was attempting something new or challenging. In the following example an educator identifies a child could have been taking a non-physical risk when creating a card for her parents.

Example Three: A card for mum and dad

Researcher- Have you observed the children taking any risks today?

Stephanie- Yeah...I observed...Alice, she'd made this...promise with mum and dad that she was going to make something special for them... she was trying to redraw the front cover of her Moana book and she was getting very frustrated because she didn't want to try to write it herself, she just wanted to know how to write it. She was just like 'No. You just need to write it' and I was like 'No, I'm not going to do that. If I do it then that's mine, it's my work' and so I drew it on the ground and she tried to copy it and because her two a's they weren't looking the same she got really upset and yeah, I guess...the risk of making those promises. She was under so much stress because she 
literally broke down in tears and I had to hold her and sing to her because it wasn't the same and she does like things to be quite structured and the same.

Researcher- And so do you think the...promise sort of enhanced that need for her to have it done?

Stephanie- Yeah, because she couldn't break her promise.

Stephanie saw that Alice was taking a risk by making a promise to her parents and in her desire to have perfect writing, the risk being that she may fail in both (Little and Eager 2015, Stephenson 2003). Alice may also have experienced a mix of fear and excitement (Sandseter 2009b) - excitement at the possibility of pleasing her parents and fear of disappointing them. Alice's experience could be considered emotional risktaking as she was emotionally vulnerable (Carter and Carter 2010) when she made the promise to her parents and when she set high expectations for herself. Alice may have also been engaged in cognitive risk-taking when she set herself the task of writing in the card, a skill she had not yet mastered and therefore was working on the edge of her competence (Bereiter 1993).

Additional examples where educators recognised children might be taking risks when doing something new or challenging included doing a puzzle, tying shoe laces and answering questions in front of peers. Educators saw these experiences as potentially risky because of the possibility of failure (Little and Eager 2015, Stephenson 2003). Educators said failing to tie shoe laces may be frustrating and upsetting for a child and when answering a question in front of peers a child may fail to answer correctly and be laughed at by their peers.

The finding that educators conceptualised children's risk-taking as non-physical builds on ideas posited in ECE literature and findings from New et al.'s (2005) study. Our findings support Stephenson's (2003) wonderings as to whether children take risks when entering play and when doing a puzzle for the first time and Tovey's (2007) proposition that children's risk-taking includes social and emotional domains. Our findings expand on New et al.'s (2005) research where educators recognised children may take risks when entering, forming and negotiating relationships. 
Our data suggests that participation in the research provoked educators to broaden their conceptualisation of children's risk-taking. Participants indicated that the researcher's example of non-physical risk-taking given prior to data collection and some questions asked during interviews had led them to think about children's risk-taking in new ways. Comments included 'You challenged us to think beyond physical risk' and 'It's only since you've started here that I've started thinking about risk in other sort of senses like social, emotional kind of avenues'. This data suggests that minimal provocation was needed to broaden educators' thinking, indicating that professional development may be an effective way to encourage educators to think more broadly about risk-taking in ECE.

In summary, our findings show that in addition to outdoor physical risky play, educators conceptualised children's risk-taking as including indoor, non-play and nonphysical experiences. This finding demonstrates that children's risk-taking is more than risky play and that exploration of a broad range of children's risk-taking warrants attention in ECE research. Although participant educators' first and most common examples of children's risk-taking were of physical and outdoor play, findings show that with provocation educators identified a broad range of possible risk-taking for children. Educators' recognition that children may engage in a broad range of risktaking, including indoors, in non-play activities and in non-physical domains, offers new insights into our understanding of children's risk-taking in ECE. Although some researchers have identified children take physical risks indoors (Kleppe 2018, Saunders 2016) and a rich-risk curriculum may invite non-physical forms of risk-taking (New, Mardell, and Robinson 2005), this is the first empirical research that we know of to uncover educators' broad conceptualisation of children's risk-taking and reveal that children's risk-taking in ECE is much broader than physical outdoor risky play.

\section{Conclusion}

Children's risk-taking in outdoor physical risky play has received attention in ECE research. Risky play research has focused on children's experiences with risky play and educators' perspectives and attitudes toward children's risky play. To the best of our knowledge, this is the first study exploring educators' universal conceptualisations of children's risk-taking. The study demonstrates that although participant educators' initial conceptualisations of children's risk-taking were aligned with those dominant in 
ECE risk research, that is as outdoor physical risky play, with minimal provocation educators recognised children's risk-taking as broader than this. When provoked, educators recognised children can take a range of risks including indoors, in non-play activities and in physical, social, emotional, and cognitive domains.

Being a small study with a focus on educators' insights, this research has limitations. As we did not interview children, we do not know how they perceived the experiences or whether their perceptions of risk-taking are consistent with educators'. However, the findings provide a useful contribution to understanding educators' views on children's risk-taking - views that may have implications for educators' practices. We argue that if educators predominantly conceptualise children's risk-taking as risky play, they may be overlooking opportunities to support, provide and encourage a broad range of children's healthy risk-taking. Findings from this study suggest further research on diverse expressions of children's risk-taking is warranted. Exploring children's perception of the kinds of risk-taking suggested by educators in this study could be a starting point for future research. Findings from this study indicate professional development may be an effective way of developing educators thinking about a broad range of children's risk-taking in ECE. 


\section{References}

Adams, John. 1995. Risk. London, UK: United College London Press.

Australian Children's Education and Care Quality Authority [ACECQA]. 2017. Guide to the national quality standards. Accessed January 2019. http://files.acecqa.gov.au.

Australian Government Department of Education Employment and Workplace Relations [DEEWR]. 2009. Belonging, being and becoming: The early years learning framework for Australia. Canberra, Australia: DEEWR for the Council of Australian Governments.

Ball, David J., Tim Gill, and Bernard Spiegal. 2012. Managing risk in play provision: Implementation guide. London, UK: Play Safety Forum.

Bereiter, C., \& Scardamalia, M. 1993. Surpassing ourselves: An inquiry into the nature and implications of expertise. Chicago, IL: Open Court.

Blais, Ann-Renée, and Elke Weber. 2006. "A domain-specific risk-taking (DOSPERT) scale for adult populations." Judgment and Decision Making 1 (1):33.

Bougheas, Spiros, Jeroen Nieboer, and Martin Sefton. 2013. "Risk-taking in social settings: Group and peer effects." Journal of Economic Behavior and Organization 92:273-283.

Braun, Virginia, and Victoria Clarke. 2006. "Using thematic analysis in psychology." Qualitative Research in Psychology 3 (2):77-101. doi: 10.1191/1478088706qp063oa.

Brown, Brené. 2015. Daring greatly: How the courage to be vulnerable transforms the way we live, love, parent, and lead. New York, USA: Avery.

Burgess, A., A. Alemanno, and J. Zinn. 2016. Routledge handbook of risk studies. England, USA: Routledge.

Carter, Patricia, and David Carter. 2010. "Emotional risk-taking in marital relationships: A phenomenological approach." Journal of Couple \& Relationship Therapy 9 (4):327-343.

Cooke, Mandy, Sandie Wong, and Frances Press. 2019. "Towards a reconceptualisation of risk in early childhood education." Contemporary Issues in Early Childhood 00 (0). doi: 10.1177/1463949119840740.

Department for Education and Skills. 2015. Curriculum for Wales: Foundation phase framework. Accessed July 2017. www.gov.wales/learning.

Doron, Claude-Olivier. 2016. "The experience of 'risk': Genealogy and transformations." In Routledge handbook of risk studies, edited by A. Burgess, A. Alemanno and J. Zinn, 17-26. England, USA: Routledge.

Dweck, Carol. 2012. Mindset: How you can fulfil your potential. London, UK: Constable \& Robinson.

Gleeve, Josie. 2008. Risk and play: A literature reveiw. Accessed July 2018. www.playday.org.uk.

Kleppe, Rasmus. 2018. "Affordances for 1- to 3-year-olds' risky play in early childhood education and care." Journal of Early Childhood Research 16 (3):258-275.

Lapkin, Sharon. 2015. "Claire Warden's nature pedagogy." Early Horizons 4 (1):4-5.

Little, Helen. 2010a. "Finding the balance: Early childhood practitioners views on risk, challenge and safety in outdoor play settings." Australian Association for Research in Education (AARE), Melbourne, Australia.

Little, Helen. 2010b. "Relationship between parents' beliefs and their responses to children's risk-taking behaviour during outdoor play." Journal of Early Childhood Research 8 (3):315-330. 
Little, Helen, and David Eager. 2015. Risk deficit disorder. Accessed July 2017. https://www.researchgate.net.

Little, Helen, Ellen Beate Hansen Sandseter, and Shirley Wyver. 2012. "Early childhood teachers' beliefs about children's risky play in Australia and Norway." Contemporary Issues in Early Childhood 13 (4):300-316. doi: 10.2304/ciec.2012.13.4.300.

Lupton, Deborah. 2013. Risk. UK, USA: Taylor and Francis.

Madge, Nicola, and John Barker. 2007. Risk and childhood. Accessed July 2017. https://www.scribd.com/document/19608791/Risk-and-Childhood-Final-Report2007.

Makovichuk, L., J. Hewes, P. Lirette, and N Thomas. 2014. Play, participation, and possibilities: An early learning and child care curriculum framework for Alberta. Accessed September 2018. www.childcareframework.com.

McFarland, Laura, and Shelby Gull Laird. 2017. "Parents' and early childhood educators' attitudes and practices in relation to children's outdoor risky play." Early Childhood Education Journal 46 (2):159-168. doi: 10.1007/s10643-0170856-8.

Morrongiello, Barbara A., Beverly Walpole, and Jennifer Lasenby. 2007. "Understanding children's injury-risk behavior: Wearing safety gear can lead to increased risk taking." Accident Analysis \& Prevention 39 (3):618-623.

New, Rebecca, Ben Mardell, and David Robinson. 2005. "Early childhood education as risky business: Going beyond what's "safe" to discovering what's possible." Early Childhood Research \& Practice 7 (2).

Ostrom, Lee T., and Cheryl A. Wilhelmsen. 2012. Risk assessment: Tools, techniques, and their applications. New Jesrsey, USA: John Wiley \& Sons, Incorporated.

Rinaldi, Carlina. 2006. In dialogue with Reggio Emilia: Listening, researching and learning. London: Routledge.

Sandseter, Ellen Beate Hansen. 2007. "Categorising risky play: How can we identify risk-taking in children's play?" European Early Childhood Education Research Journal 15 (2):237-252.

Sandseter, Ellen Beate Hansen. 2009a. "Affordances for risky play in preschool: The importance of features in the play environment." Early Childhood Education Journal 36 (5):439-446. doi: 10.1007/s10643-009-0307-2.

Sandseter, Ellen Beate Hansen. 2009b. "Children's expressions of exhilaration and fear in risky play." Contemporary Issues in Early Childhood 10 (2):92-106. doi: 10.2304/ciec.2009.10.2.92.

Sandseter, Ellen Beate Hansen. 2014. "Early childhood education and care practitioners' perceptions of children's risky play: Examining the influence of personality and gender." Early Child Development and Care 184 (3):434-449.

Saunders, Claire. 2016. "An exploration into the facilitation of risky play indoors." Reinvention: An International Journal of Undergraduate Research 9 (2).

Schoemaker, Paul J. H. 1990. "Are risk-attitudes related across domains and response modes?" Management Science 36 (12):1451-1463.

Sjöberg, L., B.-E. Moen, and T. Rundmo. 2004. Explaining risk perception: An evaluation of the psychometric paradigm in risk perception research. Accessed August 2017. http://scholar.google.com.

Smith, Stephen J. 1998. Risk and our pedagogical relation to children: On the playground and beyond. Albany, NY: State University of New York Press.

Stephenson, Alison. 2003. "Physical risk-taking: Dangerous or endangered?" Early Years 23 (1):35-43. doi: 10.1080/0957514032000045573. 
Tovey, Helen. 2007. Playing outdoors: Spaces and places, risk and challenge. New York, USA: Open University Press.

Trimpop, Rudiger. 1994. The psychology of risk taking behavior. Amsterdam, The Netherlands: Elsevier Science.

Tyagi, Vaibhav, Yaniv Hanoch, Stephen D. Hall, Mark Runco, and Susan L. Denham. 2017. "The risky side of creativity: Domain specific risk taking in creative individuals." Frontiers in Psychology 8:1-9.

Zuckerman, Marvin. 2000. Are you a risk taker? Psychology Today. Accessed August 2017. https://www.psychologytoday.com/articles/200011/are-you-risk-taker. 